\title{
O ESTÁDIO ESTÉTICO, INTERESSES E POLÍTICA: UM DEBATE ENTRE KIERKEGAARD E RANCIÈRE
}

\author{
Lauro Ericksen ${ }^{1}$
}

\begin{abstract}
Resumo: O artigo aborda a conjunção temática entre estética e política. Discute o pensamento de dois autores da filosofia contemporânea que fazem essa conexão: Kierkegaard e Rancière. Ele debate como o critério do interesse no estádio estético kierkegaardiano pode ser comparativamente analisado, no contexto estético-político de Rancière. $\mathrm{O}$ texto apresenta os regimes políticos de Rancière em alusão aos estádios da vida humana em Kierkegaard, especificamente se relacionando ao estádio estético. Objetiva oferecer um estudo atualizado da multiplicidade política contemporânea, através dos diversos interesses estéticos que influenciam a formação social. O trabalho resulta em uma abordagem estéticopolítica despida de inclinaçôes ideológicas por si mesmas, mas que possibilita a indicaçấo de vanguardas e retaguardas no pensamento político hodierno.
\end{abstract}

Palavras-Chave: Estética. Política. Metafísica. Kierkegaard. Rancière.

\section{INTRODUÇÁo}

O artigo trata detidamente sobre um possível entendimento político do estádio estético kierkegaardiano. Busca-se analisar as premissas "pós-modernas" do pensador francês Jacques Rancière, que trata da estética sob o viés político. Essa análise comparativa entre Rancière e Kierkegaard é importante, para que se possa fazer uma atualização do estádio estético kierkegaardiano em contraponto com a noção política de Rancière, a qual também se fundamenta, igualmente, numa determinação estética da realidade. Conjugando as ideias desses dois pensadores, é possível ter uma noção mais contemporânea de como a estética pode ser apropriada segundo termos políticos de sua descrição.

${ }^{1}$ Doutor, mestre e bacharel em Filosofia pela Universidade Federal do Rio Grande do Norte (UFRN). Especialista em Direito e Processo do Trabalho (Universidade Cândido Mendes - UCAM/RJ). Bacharel em Direito (UFRN). Oficial de Justiça Avaliador Federal no Tribunal Regional do Trabalho do Rio Grande do Norte - 21 a Região, Macau, RN (TRT-21). Professor de Ética na Pós-Graduação do Centro Universitário Facex (UniFacex), Natal, RN - Brasil. (iD) http://orcid.org/0000-0002-41951799 E-mail: lauroericksen@yahoo.com.br.

http://dx.doi.org/10.1590/0101-3173.2020.v43n1.08.p127

This is an open-access article distributed under the terms of the Creative Commons Attribution License. 
Pode parecer um pouco desconexo, a princípio, simplesmente correlacionar Kierkgaard e Rancière, pois não há, aparentemente, algo que os ligue de modo perene ou contundente. Isso se dá, prioritariamente, porque Rancière não cita Kierkegaard diretamente em seus escritos, e os termos por ele utilizados não remetem à tradição existencialista fundada por Kierkegaard. Dessa maneira, não parece haver uma relação direta entre o pensamento desses dois autores. Todavia, ao perscrutar melhor as obras de ambos, é possível se traçar um paralelo bem interessante.

De modo deveras similar, uma primeira impressão que a seção em andamento passa é que ela apenas se configura como uma crítica ferrenha ao entendimento estético de Rancière. No entanto, a mensagem que está subscrita liminarmente é um pouco diversa. São tecidas críticas à abordagem estética de Rancière, partindo-se de uma premissa kierkegaardiana, todavia, todos os comentários feitos, em última instância, confirmam o ponto de vista de Rancière e, apesar de isso ser algo um pouco escondido nas entrelinhas, é um dos pontos fulcrais da presente análise. Ou seja, desde pronto, há de se compreender que o intuito do trabalho não é simplesmente uma abordagem "comparativa" entre os dois pensadores, mas uma aplicação do pensamento de Kierkegaard para analisar algumas ponderaçóes de Rancière: esse é o ponto de partida fundamental da metodologia aplicada.

Didaticamente, além da presente introdução, o artigo é dividido em mais três seçôes. A próxima seção tem como escopo primordial apresentar uma síntese do pensamento de Rancière, em seus três regimes, fazendo na sequência um breve comparativo com o entendimento político de Kierkegaard, que pode ser extraído de seu estádio estético. A seção de continuação tem o intento de abordar como a política pode ser um campo de interesses (estético) multifacetado, o qual encontra caminhos diversos para se manifestar e formas bastante singulares de apresentação plural (algo não monolítico, do ponto de vista ideológico). A última seção assume o formato de exposição das consideraçóes finais sobre os principais temas já debatidos no desenvolvimento do trabalho.

\section{ESTÁDIOS E REGIMES: DELINEANDO O ESTÉTICO E O POLÍTICO}

Há similitudes estruturais entre Kierkegaard e Rancière. Por exemplo, Kierkegaard (1955, p. 30) trata de três estádios da vida humana (os estádios ético, estético e religioso); Rancière (2004, p. 20), por sua vez, aborda 
três regimes das artes: o regime ético, o regime poético (também grafado como regime representativo das artes) e o regime estético das artes (que, derradeiramente, pode ser compreendido como o regime político das artes). Didaticamente, faz-se necessário trazer breves conceituações sobre cada um desses regimes, para que o paralelo com os estádios kierkegaardianos pareça ser mais factível e de mais fácil compreensão, embora o aprofundamento no pensamento kierkegaardiano se dê de modo mais detido em seu estádio estético, servindo os demais apenas como pano de fundo para a mencionada correlaçáo alusiva trinária entre o seu entendimento e o de Rancière (no qual os três regimes se direcionam para o fundamento estético da realidade).

O regime ético das artes é aquele que se estrutura de acordo com as imagens e a respectiva formaçáo das artes a partir dela, em sua relaçáo delineadora do ethos (RANCIÈRE, 2004, p. 21). Esse regime está identificado, prioritariamente, com a metafísica platônica, na qual o modo de ser e os elementos definidores da vida em comunidade são dados por meio de imagens arquetípicas e coletivizadas. Nesse regime, as imagens são tratadas de acordo com a verdade contida em si mesmas e de acordo com os usos e os efeitos que podem ser obtidos a partir da sua manipulação (SHAW, 2015, p. 134). Em função dessas duas características básicas atribuídas ao mencionado regime, há apenas um retorno coletivo das imagens para a comunidade (elas retornam em bloco, como se fossem uma verdade unificada, sem que a sociedade possa processá-las e decodificá-las separadamente), sem que haja uma individualização de cada aspecto imagético envolvido no processo de formação da arte na própria sociedade.

O enquadramento da repercussão das imagens no ethos é mais importante que qualquer outra derivação social individualmente possível das imagens, por isso, a colocação coletiva dos efeitos das imagens é mais importante que qualquer desvio individual de sua apropriação pelos membros da sociedade. Uma estruturação societária como a da República platônica dispensa totalmente esse aspecto individualizável das artes, uma vez que o mimetismo envolvido em sua reprodução deve ter um fim adequado à própria comunidade, e não ao indivíduo. Esse é um aspecto atribuível até mesmo às artes verdadeiras, não apenas aos simulacros desorganizadores da pólis, sendo algo prevalente em sua estruturaçáo social segundo o regime ético das artes.

Ainda que esse regime se relacione de maneira deveras próxima com a arte, não é tido estritamente como um "regime das artes" por excelência (DAVIS, 2013, p. 25). Esse apontamento se baseia no apego de tal regime ao 
efeito que as imagens podem ter no ethos, ao invés de se focarem nas imagens em seus contornos artísticos propriamente ditos. Assim, a imagem da lei ou da divindade repercute de modo a ter uma tradição de usos e costumes muito mais importante, nesse regime, do que se poderia ter, caso o mero efeito de tais imagens não fosse o ponto fundamental de análise. A imagem é construída eticamente e discutida eticamente: o âmbito de sua abordagem sempre está cingido ao ético, não superando os limites de tal discussão.

Por causa da preocupação específica e centrada no efeito das imagens, no ambiente ético da comunidade, não se chega a uma politização da arte. Tampouco a arte é concebida como uma entidade discreta, apartada do próprio manejo conformativo da sociedade (CHAMBERS, 2010). As imagens possuem a tarefa de atrelar os indivíduos à comunidade segundo sistemas e preceitos éticos, sem que seja dada nenhuma outra margem de discussão, seja ela política ou não. Essa restrição na atuação do indivíduo para com a sociedade, de maneira estrita e deterministicamente relacionada, é a característica fundamental desse regime das artes, o qual descreve de forma adequada as obras platônicas.

Sinteticamente, conclui-se que, no regime ético das artes, há uma apropriação da comunidade das formas de arte, tomando as imagens como seu modo de ser coletivizado (RANCIÈRE, 2004, p. 22). Na verdade, ao se buscar apenas os efeitos garantidores da imanência imagética da arte, esse regime não confere nenhuma autonomia à arte enquanto manifestação das formas de ser individuais do homem. Seu espectro valorativo circunscreve-se apenas àquilo que a comunidade toma por artístico, em sua redoma ética.

O segundo regime das artes a ser abordado é o denominado regime poético (ou representativo) das artes. À primeira vista, com uma base etimológica de sua apresentação, já é possível identificar que esse regime se associa diretamente com as obras e o pensamento aristotélico, principalmente com A Poética. Sem embargo, diferentemente do regime ético das artes, em que a arte estava diluída no ambiente ético da comunidade, no regime representativo, há uma especificação do campo de atuação das artes, definindo-a como "belas artes". O campo próprio designado de belas artes é regido por um princípio capaz de acondicionar a definição apartada da ética (diferenciação básica do regime anterior), dando-lhe autonomia (RANCIÈRE, 2004, p. 35). O princípio representativo das artes é a mimesis (do original

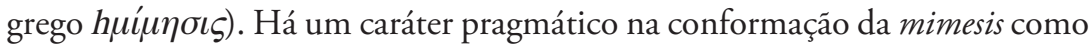


princípio representativo; ela é que possibilita a identificação e apreciação das artes, sendo capaz de julgar quais artes correspondem a quais imitaçóes.

Simultaneamente a promover a correspondência das imitaçóes a gêneros específicos, o regime representativo, através da mimesis, é capaz de avaliar, segundo critérios de boa ou de má qualidade, a extensão pragmática das artes. Assim, percebe-se que o regime representativo das artes dá privilégio ao conhecimento conceitual, em detrimento da pura forma da apreciação ética, do regime pretérito (WILLIS, 2010, p. 136). Nesse sentido, os correlativos da afecção social das artes são preferíveis à muda presença do fenômeno imagético sobre a comunidade. A avaliação da qualidade da imitação nesse regime respeita sempre as premissas aristotélicas das regras de produção das

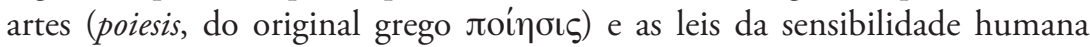

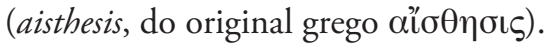

Importante destacar que, no regime representativo das artes, de modo diverso do que ocorre no regime estético das artes, analisado a seguir ainda nesta seção, aisthesis e poiesis são atreladas uma a outra, por uma contabilidade em comum, de sorte que é dada à arte uma integridade sistemática (MALIK; PHILLIPS, 2011, p. 112). Assim como a imitação é a reprodução prática da arte, a sensibilidade humana é capaz de assimilá-la e dar o retorno ao processo produtivo (poiético). Por isso, o sistema representativo se aglutina em si mesmo, de acordo com seus próprios círculos de cultura julgadores da arte que ele mesmo produz, dando a aparência de a arte ser alta cultura. A mimesis é um critério da produção ao mesmo tempo em que também se destaca como um critério válido na percepção da própria arte veiculada e apreciada.

A relação estabelecida entre os três termos (mimesis, aisthesis e poiesis) encontra-se ancorada em uma concepção delineada da natureza humana, a qual representa o pensamento de quem deve ser representado e de qual maneira o deve ser (RANCIÈRE, 2004, p. 27). Essa maneira de arranjar os atores sociais de acordo com sua representatividade expressa os acordos artísticos de como cada um deve ser concebido, nessa estrutura interligada da poiesis com a aisthesis (TANKE, 2011, p. 80), retirando-se, portanto, a possibilidade de uma compreensáo interna de cada sujeito sobre o seu papel a ser desempenhado nessa dinâmica artística, tanto no aspecto individual de sua expressão quanto, até mesmo, na expansão coletiva dessa reprodutibilidade artística. 
A definição da natureza humana como atrelada a uma hierarquia social baseada nos arranjos poiéticos finda por engessar toda a estrutura e a dinâmica das possibilidades de emancipação do homem. A partilha daquilo que é sensível, comum a todos, politicamente falando, restringe-se sobremaneira, e as dinâmicas sociais ficam impregnadas com as regras da reprodutibilidade técnica e artística. O sistema mimético se interliga de sorte a garantir a preservação dessa suposta natureza humana, dando esse lugar específico à arte, em sua concepçáo social.

Nesse contexto, há de se explanar que a sistematicidade mimética é o aspecto normativo do regime representativo das artes. Diferentemente do regime ético, a partir do qual há uma mera projeção normativa das imagens na ética da comunidade, no regime representativo, a normatividade se estabelece de modo hierárquico, em funçáo dos modos de produção da arte e de como cada um desses arranjos encontra uma sensibilidade pré-determinada para atuar. Logo, embora menos direta, a normatividade se encontra rigidamente delineada também nesse regime das artes.

Derradeiramente, é oportuno frisar que há outro regime das artes que se opóe aos dois regimes descritos anteriormente. Esse terceiro regime é denominado regime estético das artes e se caracteriza (e se diferencia dos demais) por dar espaço a uma politização do espectro artístico, do mesmo modo que garante uma individualização subjetiva de tal abordagem artística do homem e da sociedade. O elemento estético desse regime visa a romper com a apropriação comunitária das imagens operada no regime ético e com a lógica sistemática da representatividade mimética da poiesis e da aisthesis, tendo na identificação da arte com o singular a premissa básica para essa ruptura.

A característica primordial do regime estético das artes consiste em questionar inteiramente o sistema de normas, ao abolir a estrutura dicotômica da mimesis (repartida em poiesis e aisthesis), em nome de uma identificação contraditória entre logos e pathos (RANCIÈRE, 2004, p. 4). Essa abolição radical transforma de maneira singular as estruturas artísticas, tanto em termos de reprodutibilidade técnica quanto em termos de apreensão do sensível enquanto matéria partilhada entre os homens. Ou seja, é uma revolução na forma como a arte é estruturada, pensada e repassada na sociedade.

O regime estético das artes, portanto, não se identifica com nenhuma expressão comunitária datada imageticamente, tampouco encontra limites de sua definição em uma predefinição hierárquica de gêneros e de 
reprodutibilidade da arte (relacionada ao seu efeito normativo). Esse regime se desprende de todas as regras de reprodutibilidade, de gêneros, embora seja capaz de reconhecer um espaço, um locus próprio da experiência da arte (VIESTENZ, 2014, p. 16). Todavia, essa experiência da arte não é apenas uma abstração moderna metafísica da vida do homem (como os outros regimes aduzem); nesse sistema, a arte passa a se definir por si própria, não sendo mais belas artes e tampouco um anexo conjuntivo do ambiente ético da comunidade. Assim, a arte assume um caráter estético propriamente dito.

Nesse compasso, a autonomia da arte só é conquistada em seu viés estético (de desdobramento explicitamente político); ela não é capaz de adquirir esse status de outras formas, quer pela ética, quer por sua representatividade própria. Não há sistema metafisicamente arquitetado que seja capaz de prover a autonomia às artes. A autonomia da arte traz imbuída em si a noção de emancipação do homem (TANKE, 2011, p. 84). Conforme a arte se projeta estética e politicamente na sociedade, a mesma possibilidade de expressáo autêntica é fornecida ao homem, em sua apropriação estética do mundo. A autonomia da arte enquanto singularidade de um domínio próprio da experiência humana é uma ideia muito próxima da noção de emancipação do homem, bem como sua possibilidade autêntica de ter igualdade perante os outros, e de essa igualdade ser reflexamente avaliada pelos outros acerca dele mesmo.

Impende destacar que a autonomia da arte, para Rancière, designa um "modo da experiência" que transcende a esfera da arte, ao invés de identificar uma pureza estética existente apenas em si própria (DEMOS, 2013, p. 232). Por conseguinte, esse aspecto autônomo pode até designar uma autossuficiência de uma vida coletiva que não se desprende em separadas esferas de atividade, sejam elas de ordem ética, representativa, unicamente política, ou qualquer outra. A autonomia da arte no regime estético das artes faz com que ela não seja um instituto burocratizado e encapsulado em si mesmo, como rígidos paradigmas normativos dos demais regimes previamente estudados. Nesse contexto, a arte é livre para se tornar artisticamente relevante.

A estética (pós) moderna surge no cenário delineado por Rancière como uma forma de metaestética (VÉGSỐ, 2013, p. 18). A projeção autonômica da arte para além da arte deságua em um paradoxo evidente: a autonomia da arte (a tautologia de que arte é arte) se transmuta na heterodoxia da arte (a arte é não-arte). $\mathrm{O}$ aspecto mais relevante desse paradoxo é que a arte não se encontra apartada da vida (em comunidade), ou da política, ou até mesmo da religião. 
A arte está interconectada com todos esses aspectos do homem, em sua vida cotidiana, tanto quanto a filosofia, em um aspecto mais amplo, se conecta com as demais ciências (psicologia, sociologia, antropologia, física), sem lhes impor suas condiçôes ou premissas essenciais no mundo (pós) moderno.

Não obstante, há de se indicar que Rancière pontua que o regime estético das artes ainda não faz uma correlação absolutamente acertada sobre a estética e o político, ainda não há um plano de equivalência entre esses dois ambientes. Por causa das lacunas apresentadas nos três regimes por ele abordados, ele propóe uma nova partilha do sensível, que é o elemento central na tomada estética do mundo (RANCIÈRE, 2004, p. 30). Todavia, deve-se deixar notado que, mesmo sem se colocar claramente como um apresentador de um regime pós-estético das artes (ele não nomeia um quarto regime para nele se incluir), o pensamento de Rancière está mais próximo do continuísmo desse regime que da rejeição absoluta.

Assim, pode-se considerar que Rancière deflagra uma remodelagem no regime estético das artes, mas aceita a autonomia paradoxal nele inserida para, a partir daí, tecer sua problematização e fazer uma pormenorização dos tópicos mais relevantes. Seu equívoco é fazer o "pretensamente indispensável” entrelaçamento entre a sua ideologia de esquerda e a abordagem culturalista ${ }^{2}$ estético-política.

Em conclusão aos regimes de arte apresentados, é de grande valia assentar que a grande contribuição de Rancière para o presente estudo é a possibilidade de uma interpretação pós-filosófica, ${ }^{3}$ em função do regime estético das artes, a partir do qual a arte, como expressão autêntica do homem, não se restringe a um círculo cultural restrito (ético ou representativo). Esse

\footnotetext{
${ }^{2}$ Por "visão culturalista" ou "culturalismo", desde os argumentos de Kierkegaard (2010, p. 55) postos em oposiçáo à filosofia hegeliana, deve-se entender a posição superior da cultura (aquilo que é criado pelo homem) em detrimento daquilo que lhe é dado como natural. Dessa maneira, o culturalismo, utilizado na extensão do texto em desenvolvimento como equivalente do "subjetivismo cultural", encontra-se em franca oposição ao naturalismo (por vezes, denominado também como biologismo), ou seja, o elemento de base biológica que forma o homem e o circunda.

${ }^{3}$ Por pós-filosofia deve ser entendido todo o tipo de pensamento que não se conforme à centralização da filosofia como marco central do pensamento humano, de sorte que aglutine, em seu conteúdo, elementos de outras ciências humanas e, tampouco, se conforme a buscar sistemas, conceitos, essências e totalidades para a natureza humana. A antimetafísica ou a antifilosofia ainda buscam em última instância sistemas, conceitos, totalidades e essências, todavia, de uma maneira totalmente diversa, sem se prender de forma definitiva a esses elementos (CAPUTO, 1982, p. 113). Logo, ainda que se trabalhe com conceitos definidos pelos próprios autores, em conjunçôes sistemáticas, as quais encontram algum vislumbre de totalidade, a essência dessas consideraçóes não se torna absoluta por uma definiçáo dada sobre si-mesma.
} 
aspecto ampliativo da arte dá margem para que se possa ter em relevo o pensamento de Kierkegaard (1955, p. 20) na atualidade, dando-lhe o mesmo status de relevância que é conferido ao entendimento de Rancière sobre esse tópico de debate.

A aproximação entre o pensamento de Kierkegaard e o de Rancière, tal como indicado, não é algo meramente arbitrário ou aleatório. $\mathrm{O}$ fundamento de tal "comparaçâo" "4 reside em dois motivos. O primeiro deles diz respeito ao fato de que ambos não são "filósofos", no sentido técnico ou estrito da palavra, porque seus escritos e pensamentos se direcionam a vários eixos diferentes, da literatura à política. Em segundo lugar, os dois pensadores deixam em aberto a possibilidade de se atrelar política e estética como um dos planos da vida prática do homem. Nesse sentido, é possível se pensar o posicionamento no espectro ideológico de Kierkegaard sob um viés diferenciado, o qual não esteja necessariamente atrelado ao pensamento da esquerda política (apesar de ele ser considerado um hegeliano de esquerda, reunido no rol dos pensadores, como, por exemplo, Marx e Nietzsche, os quais aceitam a dialética hegeliana, mas rejeitam o conteúdo do pensamento de Hegel), já que Kierkegaard, usualmente, não é tido como um pensador de "esquerda", como Marx é enquadrado, exemplificativamente. O pensamento de Kierkegaard, por mais que possua várias nuances políticas, é muito mais aberto e pouco dogmático, característica que o faz de difícil enquadramento no espectro político costumeiro (se de esquerda ou não).

Além da simetria entre os estádios e os regimes (em Kierkegaard, há três estádios da vida humana, enquanto, em Rancière, há três regimes das artes), é de se ter em relevo que a noção de vanguarda estético-política, como colocada por Rancière, é transformada em uma retaguarda, quando se analisa o pensamento de Kierkegaard (ROBERTS, 1987, p. 12): afinal, ele é a resistência nesse processo dialético da análise estético-política por ora empreendida. Explicando-se melhor: tendo-se em vista que Kierkegaard (2010, p. 133) não almeja o desenvolvimento do sistema hegeliano, porém, um retorno às premissas essenciais do cristianismo, o seu pensamento não é um avanço (uma vanguarda), quando posto em confronto com a metafísica hegeliana. Assim, o pensamento de Kierkegaard é uma retaguarda ao sistema hegeliano e às suas derivações (estéticas, políticas e sociais, de uma maneira mais ampla possível).

\footnotetext{
${ }^{4}$ Deve-se ponderar que não é uma simples comparação despida de nenhum pressuposto interpretativo; pelo contrário, metodologicamente, a proposição do trabalho consiste em analisar o pensamento político e estético de Rancière sob a ótica perspectivista de Kierkegaard.
} 
Vanguarda, na dinâmica de Rancière, é uma proposição valorativa da estética presente, ou, melhor dizendo, uma renovação da proposta estéticopolítica (SANDERS, 2009, p. 15) na forma de emancipação do homem. A emancipação é um conceito central na discussão estética e política de Rancière, a qual, na visão ora apresentada, encontra seus meios de ocorrência, através das inovaçóes e implementaçóes trazidas pelas vanguardas. Sem a vanguarda e a evolução do pensamento, ainda que pós-filosófico, não há emancipação possível ao homem. Emancipação é o estágio político no qual cada um é capaz de avaliar a igualdade existente entre si e ser avaliado, igualmente, pelos demais (BREAUGH; LEDERHENDLER, 2013, p. 95). Embora Rancière textualmente não forneça boas explicaçôes do que é efetivamente vanguarda, nem mesmo como se dará a emancipação do homem ${ }^{5}$, a conexão entre os dois vocábulos é essencial para o seu pensamento.

Nessa perspectiva, o culturalismo de Rancière não se furta a dar o crédito da valoração da cultura aos artistas, tal como propóe, por exemplo, Heidegger (MALPAS, 2006, p. 7). Trazendo os posicionamentos estéticos para o campo político, Rancière se desvencilha dos arcaicos posicionamentos financeiros ou economicistas da política, para dar vazão a outras formas de pensar. É justamente nessa abertura que a retaguarda kierkegaardiana encontra lugar dentro da análise feita de Rancière, no trabalho em andamento.

Rancière não rejeita a perspectiva relativista e culturalista de Kierkegaard (1955, p. 47) e, em grande monta, de Heidegger também (VADÉN, 2014, p. 101); ao contrário, ele abraça essa perspectiva pós-filosófica, retirando da própria filosofia a égide julgadora sobre as demais ciências. Sem o apanágio de ser a ciência-mestra, a partir de qual todas as formas de conhecimento derivam ou, em menor grau, devem prestar obediência, o pensamento de Rancière dá lugar a vanguardas (como pode ser compreendido seu próprio pensamento, em seu viés ideológico maoísta). ${ }^{6} \mathrm{E}$, de modo similar, o avanço nesse campo

\footnotetext{
${ }^{5}$ Rancière (2004, p. 45) salienta que a emancipação do homem passa pela sua politização e por uma melhor partilha do sensível, mais adequada e equilibrada. No entanto, suas proposiçôes são deveras vagas e pouco elucidativas, de sorte que tais palavras se perdem em uma conceituação abstrata pouco prática, na realidade.

${ }^{6}$ A visão de Rancière era declaradamente maoísta, em seu início, principalmente após o seu rompimento com Althusser (que era seu tutor intelectual e stanilista), e ainda não há relatos até o presente momento de que ele tenha reformado tal posicionamento ideológico, apesar das atrocidades cometidas por esse regime político. Seu entendimento maoísta se punha em oposiçáo ao stalinismo dominante na academia francesa e diz respeito à sua noção universalista de que a revolução (e a compreensão da realidade) é não elitista, de modo que todos, principalmente os estudantes, são partes indispensáveis no seu desenvolvimento "cultural" e político. O uso do maoísmo como um elemento caracterizador
} 
do pensamento dá espaço também a se pensar retaguardas, como está sendo caracterizado o pensamento de Kierkegaard. A importância de colocar o pensamento desses dois autores em relevo, portanto, náo consiste apenas em uma crítica diletante a Rancière, porém, em dar o crédito devido a ele, que compreendeu em grande monta as diretrizes de Kierkegaard (1955, p. 78). Entretanto, não se pode se furtar a traçar as críticas devidas a algumas noções especificas da estética-política de Rancière, como será feito mais adiante.

Em um plano marxista de análise, sob a perspectiva de Rancière, a vanguarda está mais próxima da "ruptura" da superestrutura socialmente posta, e isso, embora seja algo que ele não afirme categoricamente, está implícito em sua defesa ideologicamente referida. Todavia, é interessante observar que a proposta da retaguarda kierkegaardiana nâo pode ser identificada com a noção elementar de "continuidade histórica" do hegelianismo, pois ela é tida como uma oposição à metafísica hegeliana, a qual se tornou prevalente durante um tempo considerável na tradição filosófica.

Assim, a vanguarda de Rancière (2004, p. 41) e a retaguarda de Kierkegaard (1955, p. 64) assumem valoraçôes equivalentes, no plano estéticopolítico, a despeito de seus conteúdos serem diferentes em sua "essência" (elas são equidistantes em suas ponderaçôes, o que é relevante para a análise em progresso). Num mundo livre onde seja possível a defesa da vanguarda de Rancière, por simetria, é necessário que a retaguarda kierkegaardiana também esteja colocada dentro do horizonte mais amplo de possibilidade. Dessa maneira, a perspectiva heideggeriana de um horizonte de possibilidades amplo e valorativo se torna eficaz e pujante, em sua argumentaçáo antimetafísica. Se há alguma liberdade possível ao homem, na pós-filosofia e na pósmodernidade, ela certamente será subjetiva e valorativa, embora não arraigada ideologicamente a nenhum viés predeterminado. Liberdade, nesse sentido, pode estar tanto na vanguarda quanto na retaguarda, cabendo a cada um sopesar cada aspecto dessas posiçóes estético-políticas possíveis e por elas escolher.

$\mathrm{O}$ vanguardismo de Rancière tem seu mérito até o ponto em que ele não desmerece a valorização estética da arte. Até esse momento, seu

de seu pensamento serve didaticamente para conformá-lo como sendo uma vanguarda, em oposição dialética ao pensamento cristão de Kierkegaard, definido, precipuamente, como uma retaguarda nessa empreitada conceitual.

7 O plano filosófico marxista pốe em relevo períodos de continuidade e de ruptura, de sorte que a história transcorre segundo esses dois momentos dialeticamente opostos. 
pensamento está posto de maneira condizente com os já mencionados predecessores dessa forma de colocar a estética e a ontologia (Kierkegaard e Heidegger). Todavia, Rancière começa a tocar fora da curva, quando fixa seu critério estético numa política unilateral vinculada ideologicamente. $\mathrm{O}$ descortinar da contemporaneidade (a qual Rancière se recusa a aceitar como "pós-modernidade") não pode se afastar da multiplicidade e da variedade valorativa já designada por Kierkegaard (1955, p. 36), em seu perspectivismo ardente. ${ }^{8}$ Assim, o criticismo da presente seção se direcionará em tal sentido, buscando corrigir as distorçóes ideológicas operadas por Rancière, dando uma recondução às valoraçôes mais livres em uma visão kierkegaardiana desprendida de tal apego ideológico.

Importante destacar, nesse compasso, que o critério estético adotado por Kierkegaard (1955, p. 24), portanto, se diferencia fortemente de outros critérios estéticos adotados por alguns outros pensadores contemporâneos, a citar, como exemplo de tal vertente de pensamento, Jacques Rancière. O ponto principal na estética proposta por Rancière, além do seu flagrante espectro político de viés de esquerda, que, a princípio, não é relevante para o argumento a ser levantado, é que a estética é o compartilhamento do sensível.

De maneira um tanto quanto simples, aquilo que é compartilhado de modo sensível entre os homens serve como critério para o julgamento de que algo a ser apropriado, culturalmente, possa vir a ser esteticamente relevante ou não. Logo, há de se perceber que o critério de relevância para a tomada estética de tal estádio específico da vida humana é o interesse simples e puro, como designado por Kierkegaard (1955, p. 25), o que destoa flagrantemente de qualquer compartilhamento imediato. Assim, na visão kierkegaardiana, por mais que ele se empenhe em ter um pensamento voltado para a formação cultural e valorativa de sua própria época, mirando, até mesmo, a formação de uma cultura cristã posterior mais extensa e acolhedora, não se atém a tal compartilhamento, como se ele fosse uma pressuposição do sensível, conforme aponta Rancière. Muito pelo contrário, a posição firmada por Kierkegaard coloca na subjetividade de cada um o critério mais simples, para que um interesse qualquer seja estabelecido, determinado e, por fim, perseguido por cada homem.

\footnotetext{
${ }^{8}$ Por perspectivismo ardente se compreende o entendimento de que não há posicionamentos que sejam filosoficamente absolutos, em termos metafísicos, de acordo com sistemas e conceitos pré-definidos. $\mathrm{O}$ termo possui uma correlação próxima do étimo "relativismo ardente", o qual foi evitado, sob pena de soar pejorativo ou muito disperso, em sua conceituação.
} 
Como já referido anteriormente, Rancière sempre conjuga dois temas básicos em seus escritos: política e estética. Com a obra A Partilha do Sensivel não é diferente. Rancière tenta aprofundar o argumento de como é possível traçar a identificação das artes através de sua classificação como modos de fazer, ou seja, como colocá-la como uma forma de apresentação daquilo que é comum. Apresenta-se, por conseguinte, o conceito de "partilha do sensível" (RANCIÈRE, 2004, p. 31), a base em comum tanto para os elementos estéticos quanto para a política. Ele vai além nesse conceito e pontua que este é algo que representa aquilo que é comum intersubjetivamente, ou seja, é um modo de compartilhamento encontrado na política e na estética.

Todavia, diferentemente de Walter Benjamin, que promove uma estetização da política (BLOCH, 1977, p. 66), Rancière vê a questão política e a questão estética de uma maneira diferenciada, não dando uma consequência à reprodutibilidade técnica como o meio de expressão do ser humano em uma acessibilidade universalizada, tal como concebia o referido pensador. Ele vai pensar mais propriamente a efetividade desses paradigmas estéticos e suas repercussóes políticas, ou seja, pensa de forma ainda mais desprendida essa comunhão estético-política.

Retomando a questão da contextualização da obra em comento em referência com as demais produçóes acadêmicas de Rancière (1995, p. 7), é importante pontuar que o conceito acima descrito não foi pioneiramente utilizado na obra por ora comentada. Na verdade, o referido conceito já havia sido usado na obra Políticas da Escrita, mais especificamente em seu prefácio. No entanto, é de grande valia ressaltar que, na obra $A$ Partilha do Sensivel, o conceito homônimo ao título é colocado de uma forma diferente daquela empregada de forma inaugural. Na verdade, na obra em relevo, o conceito de partilha do sensível é semelhante ao adotado por Rancière (1996, p. 17) e traduzido por "divisão do sensível", conceito o qual aparece na obra $O$ Desentendimento: Politica e Filosofia. De sorte a se ter em mente que a partilha do sensível, na sua obra mais recente, está atrelada ao debate ocorrido em torno da "crise da arte" e como se é possível que a estética, em comunhão com a política, possa se espraiar nos domínios em que se desenrolam as mais pujantes promessas e emancipaçôes da humanidade.

Retomando os argumentos de Kierkegaard (2011, p. 47), é importante denotar que o viés do subjetivista pensamento kierkegaardiano não trata de nenhuma espécie de isolacionismo ou de algum elitismo deliberado (como alguns acusam Platão, quando eles estudam ou interpretam $A$ República, por 
exemplo). Apenas o elemento da subjetividade sendo a verdade se distancia de modo firme de uma posição de compartilhamento de elementos sensíveis, como propôe Rancière. Certamente, há de se rememorar, como já indicado, que o mencionado pensador possui projeçôes políticas as quais escapam à mera conceituação que ele dá de "compartilhamento do sensível”, pois a estética para ele se transmuta facilmente em política e, em certo sentido, em proselitismo ideológico marxista, algo que não se verifica em Kierkegaard, pois não há nenhum espectro ideológico, nem de esquerda nem de direita, flagrantemente identificável em suas obras, embora alguns comentaristas se arrisquem a dizer que ele era de direita (FEUER, 2010, p. 53). ${ }^{9}$ O seu comprometimento mais amplo e mais solidificado é identificado com o cristianismo, de uma maneira mais simples e acessível possível (KIERKEGAARD, 2010, p. 88), sem misturá-lo (indevidamente, saliente-se) com nenhuma perspectiva política propriamente dita. Pode-se dizer que a sua defesa clara e explícita do cristianismo o blinda da tentação do proselitismo ideológico, que é o mote de alguns pensadores, como é o caso do já mencionado Rancière.

Alguns autores argumentam que a perspectiva estética colocada por Rancière é inovadora, porque ela vai além dos limites do que é comumente definido como artístico (MAY, 2010, p. 108), ou seja, usualmente, seria possível asseverar que o mencionado autor indica um parâmetro estético que perpassa os limites da arte ou da discussão artística, por assim dizer. Assim, a estética para ele, seria a "configuração do mundo comum" (ROSS, 2012, p. 91), algo que desenvolveria de um modo muito mais avançado, para além dos sistemas hegelianos de definição filosófica, o que seria a estética e os seus conteúdos mais pormenorizados da realidade.

Essa forma de argumentação em prol de uma defesa inovadora da perspectiva estético-política de Rancière é falha em si mesma, por dois motivos. O primeiro motivo consiste em afirmar que a noção estética de

\footnotetext{
${ }^{9}$ Lewis Feuer (2010, p. 54) aponta Kierkegaard como um direitista, pelo fato de ele nunca ter sido um ativista em seus ideais políticos e pelo fato de o próprio Kierkegaard náo identificar os elementos políticos com a verdade eterna, sendo esse, portanto, um tópico sempre marginal ou secundário em seus escritos e na interpretação que podem ser deles extraídos. Mais do que um direitista (termo que usualmente assume uma conotação econômica), Kierkegaard é colocado por Feuer como sendo um "conservador", no sentido em que os usos e costumes de sua comunidade cultural não devem ser revolucionados por um líder ou por quem assuma essa posição de dirigente político. A conservação de certos valores, para Kierkegaard, é adequada e é algo digno de incentivo: esse é o seu viés conservador, politicamente falando. Essa indicação de Feuer é bastante interessante, não apenas porque há um predomínio da esquerda política, quando se fala em dialética, bem como também porque Kierkegaard, como um "cristáo conservador", faz valer seu existencialismo em contraposição aos militantes ateus, como Sartre, por exemplo, de uma forma bem mais assertiva e bem posicionada no espectro político.
} 
Rancière é inovadora, por ter uma noção primariamente não-artística (ou além da esfera artística). Essa afirmação é notoriamente inválida, não só por autores existencialistas, como Kierkgaard, identificarem o estádio estético como não sendo essencialmente artístico ${ }^{10}$, bem como pela noção elementar de Friedrich von Schiller (1995, p. 44). Segundo Schiller, a noção estética combina uma noçấo temporal presencial e de liberdade do homem. Dessa maneira, sua educação estética (a qual não depende, necessariamente, do elemento artístico ${ }^{11}$, propóe uma abertura para se pensar a estética para além dos limites do que é comumente definido como arte ou atrelado a uma apreciação artística da natureza. Por isso, verifica-se que a separação entre estética e arte se dá em um momento bem anterior à noção estético-política de Rancière.

Em momento posterior, observa-se que o segundo motivo pela incoerência do argumento apresentado por Ross é que, apesar de a noção estética de Rancière não se ater, unicamente, ao aspecto artístico (tentar de certas formas se libertar de tal pecha), ela recai, de modo infame, no aprisionamento político de tal análise. Ou seja, ainda que a perspectiva enunciada por Rancière não possa ser enquadrada apenas no espectro artístico de análise da estética, ela acaba sendo refém dos enunciados políticos do mencionado pensador. Logo, pode-se perguntar: do que adianta se libertar das amarras da estética hegeliana ${ }^{12}$, mas recaindo em uma análise política da realidade atrelada necessariamente a um espectro político notadamente identificado (e defendido pelo próprio autor) como de esquerda, em sua totalidade filosófica? Em síntese, indaga-se se Rancière não troca somente uma vinculação estético-

${ }^{10}$ Isso não significa afirmar que Kierkegaard (1943, p. 91), eventualmente, faça associaçóes e correspondências entre a pecha artística ínsita e a representaçâo estética da expressividade humana, como ele o faz, ao descrever Don Giovanni de Mozart, quando ele coloca a música como elemento sedutor da formação desse ícone do estádio estético na ópera do mencionado compositor. No entanto, em uma perspectiva mais ampla esposada na obra Estética y Ética, o estádio estético pode até corresponder ao artístico, mas sem que essa vinculação seja necessária ou peremptória, apenas possível (e desejável, no caso específico do sedutor - Don Juan, e, quiçá do próprio Kierkegaard, na sua obra mais reflexiva O Diário de um Sedutor, ou até mesmo em suas obras mais "literárias", como Temor e Tremor).

${ }^{11}$ A perspectiva de Schiller, por ora apresentada, foi pensada em um momento histórico e cultural bem anterior ao de Rancière, pretérito, e bastante, até mesmo ao momento em que Kierkegaard escreve sobre o tema em relevo. Assim, o que é apresentado por Rancière como sendo inovador náo é nada mais do que uma breve reciclagem dos argumentos de Schiller, postos em uma linguagem (filosófica) pós-moderna.

${ }^{12} \mathrm{O}$ maior intento de Rancière, ao tentar prover um pensamento estético-político que nấo fosse sistemático e que, mesmo assim, pudesse dar uma resposta ideologicamente aceitável à esquerda pósmoderna. Ele tentava um contraponto com a política da esquerda posterior aos movimentos de 1968, a qual ainda sustentava um viés stalinista, em seu discurso ideológico. 
filosófica (de raiz hegeliana) por uma "amarra estético-política baseada em propostas marxistas" (ou marxianas, por assim dizer).

Essa é uma pergunta que a maioria dos intérpretes de Rancière se furtam a responder, justamente por já estarem alinhados ideologicamente com a própria estética do mencionado autor. No entanto, com a proposta de análise estética desse estádio da vida humana, sob a batuta existencial de Kierkegaard, é possível se abstrair de tal perspectiva totalizante (sob o enunciado político), a fim de se obter um resultado muito mais relevante e interessante, sob a sua perspectiva culturalista. Não há um culturalismo múltiplo e diversificado em Rancière, apenas um monólito estético-político (LUXON, 2013, p. 284), o qual, na sua ânsia de superar a estética do artístico (ao menos numa primeira abordagem, embora meramente aparente), restringe-se somente a direcionar os desígnios da sociedade ao espectro ideológico da esquerda política. Assim, as premissas estéticas de Rancière acabam por aprisionar seu pensamento a um dogmatismo político e ideológico que veda a si mesmo superar as amarras que o esteticismo artístico de outras épocas filosóficas nem sequer impunha aos pensadores. Ao invés de parecer libertador, em seu viés político, o pensamento estético de Rancière é aprisionador, em seu próprio sentido ontológico.

\section{INTERESSES E POLÍTICA: DA ESTÉTICA E SEU PLURALISMO}

O pensamento culturalista de Kierkegaard pode ser compreendido pela conjunção de interesses em comum, que define, em um primeiro plano, a perseguição dos interesses próprios de cada homem. ${ }^{13}$ Em segundo plano, quando há a coincidência de interesses, ocorre a formação de círculos de culturas específicos que vão se amontoando gradativamente até que se forme todo o espectro cultural que se distende da forma mais variável e diversa possível. Nesse sentido, a multiplicidade dos elementos culturais, formados esteticamente, não se dá no interesse em si mesmo, como se a gênese do interesse antecedesse, por si mesma, a própria cultura na qual o interesse se insere.

Todavia, há de se fazer um breve adendo, para que a compreensão do estádio estético em Kierkegaard seja mais efetiva, tanto por si quanto ela servir

\footnotetext{
${ }^{13}$ Ainda que o interesse seja próprio de cada um, a figura cultura inserida nessa perspectiva perdura por um tempo significativo, pois se repete em cada açấo culturalmente alicerçada (MOONEY, 2012, p. 68). Assim, seus escritos (principalmente os pseudonômicos) adquirem uma "presença cultural" de longa persistência no imaginário comum, retratando figuras que se adequam facilmente ao cotidiano dos seus leitores.
} 
de espeque para a análise das ponderaçóes de Rancière. $\mathrm{O}$ estádio estético, para Kierkegaard, caso seja tomado unicamente por si mesmo, apartado de qualquer outra reverberação dos demais estádios (ético e religioso), deve ser tido como uma apresentação do homem "essencialmente" negativa. Tal apresentação de um sentido negativo é compreendida a partir da geração tediosa e de fastio para com a existência, causada pelo encapsulamento nesse estádio. Ou seja, a perseguição de modelos e de perspectivas unicamente estéticas faz com que tal estádio fomente a incompletude da vida do homem e seu aprisionamento numa sensibilidade inerte e vazia. O estádio estético se mostra carente e dotado de uma irresponsabilidade patente para com a assunção da projeção existencial do homem, quando tomado isoladamente. ${ }^{14}$

Sem que haja a integração do estádio estético com o religioso (já que, com o estádio ético, ela será eventual e não necessária apenas suficiente de um ponto de vista "lógico"), náo se pode falar em uma existência realmente "valorosa" nos padróes kierkegaardianos, de maneira que os demais interesses que são buscados (ou até mesmo podem vir a ser buscados), sob a perspectiva política, inclusive, perdem totalmente seu sentido e a sua noção de prestígio, diante da vida do homem. De modo inicial e perfunctório, o estádio estético é o primeiro passo que vem a dar forma à existência humana, todavia, tomado por ele mesmo, é apenas vazio e incipiente -, se o estádio estético for prevalente e dominante em sua acepção "solipsista", focada unicamente nesse estádio e sem qualquer conexão com a reflexividade mais profunda e relevante ofertada pelo estádio religioso.

Após essa breve explanação sobre o caráter negativo do estádio estético, para Kierkegaard, caso ele seja tomado com exclusividade e sem nenhuma ponderação mais adequada, há de se dizer que o pensamento de Rancière indica que o elemento estético parte de uma necessidade indispensável do compartilhamento daquilo que é comum a todos, pois todos são capazes (em seu aparato perceptivo) de sentir. Para ele, portanto, o mero sentir humano já se transforma diretamente em um envolvimento político, obrigatoriamente de esquerda, ressalte-se.

\footnotetext{
${ }^{14}$ Assim sendo, por mais que o artigo tenha como enfoque primordial o estudo do estádio estético, em toda a sua extensão ele deve ser compreendido como o estádio estético já coligado ou fundido com outros elementos de uma expressão existencial mais completa do homem (por meio de sua conexão com o estádio religioso ou ético, no que for cabível). Sem que se recaia na preconcepção crítica que o artigo se foca em um elemento negativista do pensamento kierkegaardiano e o utiliza sem as devidas atualizaçóes ou consideraçóes conceituais que sejam capazes de fornecer um entendimento mais substancial de questōes tão fundamentais e relevantes para tal estudo.
} 
Toda injustiça contida no mundo ("pós-moderno")15, segundo Rancière, deriva da incorreta partilha do sensível. Ele não explica claramente o que é o sensível ${ }^{16}$ a ser partilhado, haja vista que esse termo parece ser bem diverso da noção kantiana de sensibilidade (espaço e tempo) compartilhável entre os homens. Todavia, parece que sensível, na linguagem de Rancière, está próximo do substrato material disponível aos seres humanos a ser trabalhado tecnicamente por eles, em prol de seu desenvolvimento. A incorreta partilha dos recursos que formam o sensível seria a fonte da miséria humana (desigualdade material, num sentido aristotélico $)^{17}$ e de todas as desgraças políticas da humanidade. Enquanto houver os que têm parte do sensível, e aqueles que não possuem uma parte dele, sempre haverá desigualdade entre eles, um modo de dominação patente estabelecida de forma relacional (MCNAY, 2014, p. 160). Uma partilha que se adequasse, tanto estética quanto politicamente, aos anseios de todos, igualmente, seria o objetivo primordial das ponderaçóes de Rancière acerca desse tema.

Diferentemente, em Kierkegaard (2010, p. 90), o interesse possui sua gestação no âmago da subjetividade de cada um, tendo o seu leque de possibilidades mais amplo quanto possível, de sorte que o resultado de tal premissa é que o que deriva de cada interesse individual, quando arregimentado no seio da sociedade, é a múltipla pluralidade de interesses culturalmente expressos, não sendo algo unicamente que reflita aquilo que é compartilhado sensivelmente, como diria Rancière. $\mathrm{O}$ interesse primário de Rancière é o consenso, o qual mantém afastada a possibilidade de a sociedade se dissolver coletivamente, em diferentes direçôes e interesses (BROCKMAN, 2013, p.150). Por causa dessa busca pelo consenso, o pensamento de Rancière não consegue dar conta da multiplicidade estética fornecida por Kierkegaard (1955, p. 69), entretanto, necessita sempre negar esse leque amplo de possibilidades

\footnotetext{
15 Rancière não se vale do termo "pós-moderno" ou "vanguarda", para definir seu pensamento. Contudo, esses termos indicam efetivamente aquilo que ele tenta descrever e, por causa disso, são utilizados adequadamente no trabalho em desenvolvimento.

${ }^{16}$ Ainda que o próprio Rancière nâo explique claramente ao que o termo "partilha do sensível" se refere, pode-se fazer uma leitura "marxiana", na qual o termo equivale à "divisão social do trabalho" (HIRVONEN, 2014, p. 161). Ele diz respeito à distribuição de competência e de ordenaçôes políticas e sociais, às formas e lugares de participação política e econômica, à inclusão e à exclusão dos indivíduos, em síntese, ao mostrar e ao esconder das formas e dos corpos sociais e políticos na sociedade como um todo.

${ }^{17}$ É importante destacar o sentido aristotélico que Rancière dá aos seus escritos políticos, pois ele é um grande crítico do platonismo, aceitando a conjuntura aristotélica para descrever a realidade política conjuntural.
} 
existenciais, para que seus objetivos políticos sejam efetivamente conquistados, algo impossível sem a sua noção de consenso (estético e político).

A consecução de certos interesses pode até mesmo dar azo à formação estética de elementos políticos, seguindo o viés kierkegaardiano de uma interpretação estética da realidade sensível, no entanto, não se pode afirmar, categoricamente, que a simples existência de interesses que venham a ser compartilhados dá azo a tal formação ideológica ou política (HANNAY, 1999, p. 268). Aliás, não há nenhuma necessidade em se compartilhar aquilo que se sente, tampouco se pode desdobrar o entendimento de que o simples compartilhamento já gerará implicaçóes políticas. $\mathrm{O}$ mero sentimento não possui um modo de compartilhamento só por ser um sentimento, bem como tudo que é partilhado não é político por estar sendo repartido entre os membros de uma determinada sociedade. Nem tudo que é posto para as demais pessoas, obrigatoriamente, assume um viés político; a própria arte, abstratamente e subjetivamente concebida, pode ser exposta publicamente como uma simples expressão artística subjetiva, sem nenhuma intenção além do seu mero mostrar, um mostrar sem dizer nada além.

Tratar a questão estética sob tal fundamento é reduzir de modo abrupto todas as possibilidades existenciais que cada ser humano possa ter por um interesse diverso, aliás, por interesses que sejam sensíveis, mas que não possuam um cunho político evidente ou flagrante. Não se depreende, portanto, da mera confirmação de um interesse que venha ou, ao menos, que possa vir a ser compartilhado, que haja um elemento político dominante ou que haja qualquer sorte de direcionamento político em tal premissa estética kierkegaardiana. ${ }^{18}$

As possibilidades existenciais conferidas ao estádio estético pela interpretação por último ofertada são bem mais amplas que a explicação fornecida por Rancière. A interpretação estética kierkegaardiana inclui enquadramentos políticos, científicos, filosóficos, esportivos, cômicos, trágicos, dentre uma infinidade de outros vieses possíveis, desde que denotem algum interesse, quer relevantes, quer irrelevantes, em termos políticos. Ela não se limita apenas a uma análise política dos interesses humanos.

\footnotetext{
${ }^{18}$ Há quem aponte, no entanto, que negar um caráter natural e essencial à política é negar à política qualquer poder de emancipação (COPJEC et al.; 2011, p. 94). Ou seja, dar qualquer contorno apolítico ou pré-político ao entendimento do homem sobre si mesmo é condicioná-lo às situaçôes opressivas que pretensamente estáo sendo reproduzidas culturalmente, segundo o pensamento de Rancière e de alguns dos seus seguidores (conforme citado).
} 
Em conclusão, pode-se asseverar que a grande variedade de interesses do estádio estético depreende que nem todos os interesses humanos possuem, necessariamente, um espelho político daquilo que é sensível na vida do homem e que não há tal correspondência, de forma irrefreável, como aponta Rancière. Compreender o estádio estético sob a lente de Rancière equivaleria a dar uma essência (pré) política ${ }^{19}$ ao homem, antes mesmo de sua existência, e antes mesmo de seu aprofundamento subjetivo em si mesmo, como propóe Kierkegaard.

O estádio estético para Kierkegaard, tal como já mencionado, forma a maioria das ocupaçôes humanas possíveis, porque o interesse é o fator determinante mais elementar que pode ser encontrado na conduta e nas ações humanas e que ajuda a delinear toda a expressão de tal estádio. Dessa maneira, não há como se buscar a redução desse estádio da vida humana, tão rico por si mesmo, apenas a contornos políticos e ideológicos, para que se possa encontrar uma estética do compartilhamento. Há de se ter em conta que, na interpretação proposta por Kierkegaard (1955, p. 70), o sensível é parte do estádio estético, aliás, pode-se sustentar que é grande parte desse estádio, mas nem por isso tudo que está nele contido é compartilhado de sorte a se estender para os campos da política ou da luta política, por assim dizer, de um modo mais adequado à inclinação e defesa do proselitismo ideológico de Rancière. $\mathrm{O}$ problema de Rancière náo consiste, principalmente, em identificar os elementos da sensibilidade humana como algo atrelado à estética do homem; o grande problema em sua argumentação estético-política é identificar unicamente esses elementos com a estética, inexorável e irremediavelmente, para posteriormente encapsulá-los em seu discurso ideologicamente comprometido com certo fim específico.

Diante da análise comparativa feita entre a proposta estética de Kierkegaard com a proposta estético-política de Rancière, pode-se extrair o entendimento, mais importante até mesmo que a própria comparação em si mesma, por assim dizer, de que Kierkegaard, por meio dessa abordagem, busca reafirmar, sequencialmente, o adágio de que a subjetividade é a verdade, sem, no entanto, precisar rememorar essa marcação de modo expresso. A assunção

\footnotetext{
${ }^{19}$ Por pré-política se indica um sentido de ser do homem comparável ao status pré-ontológico de compreensão do homem sobre si mesmo (HEIDEGGER, 2008, p. 50), sob um viés heideggeriano. Todavia, essa interpretação é muito além das possibilidades do homem, pois suplanta a própria possibilidade pré-ontológica de compreensão de mundo, um mundo culturalmente aberto, e não identificado com pressuposiçốes objetivistas. Esse, aliás, é o entendimento tanto de Heidegger quanto de Kierkegaard a respeito desse tema.
} 
de verdade na subjetividade náo significa, como destacado de maneira sutil, anteriormente, que ele negue a possibilidade de uma cultura ou de um espaço coletivo de abordagens e de discussão acerca dos interesses e das construçôes sociais esteticamente dispostas, aliás, pelo contrário.

Kierkegaard (1955, p. 79) não rejeita ou renega o elemento cultural na disposição estética de forma alguma: as conclusôes que podem ser desdobradas da comparação por ora estabelecidas se inclinam nessa perspectiva, haja vista que todo o elemento cultural está desenvolvido, de modo basilar, na conjunção dos interesses dos homens. Os indivíduos são capazes de expressar os seus interesses culturais livremente, como um produto de sua subjetividade, e, em última instância, eles também são um produto de todas as vivências existencialmente relevantes de suas vidas.

\section{ConsideraçốEs FinaIs}

Derradeiramente, há de se explicar o motivo pelo qual a "comparação" entre Kierkegaard e Rancière foi feita, neste breve artigo. $\mathrm{O}$ intuito de tal análise comparativa consiste em afastar uma possível interpretação da estética kierkegaardiana que venha a limitá-la a um único viés político. Em última análise, Rancière até aceita a noção de interesse kierkegaardiano, como elemento que reparte o sensível; ele apenas rejeita que haja outras derivaçóes do interesse, além de seu aspecto político. Por causa dessa rejeição, a presente seção tratou de apontar os deslizes de Rancière em sua abordagem estéticopolítica, a fim de demonstrar que um retorno ao texto kierkegaardiano já fornece uma interpretação satisfatória do estádio estético.

Assim, esse estádio deve ser compreendido em toda a sua multifacetada existência, a qual possibilita ao homem várias escolhas e muitas oportunidades de vivenciá-las, sem se preocupar, obrigatoriamente, com suas implicaçóes políticas. O esteta, no sentido proposto por Kierkegaard, importa-se mais com seus próprios interesses que com as consequências desses interesses, coletiva ou individualmente falando.

De modo conclusivo, há de se indicar que o principal elemento que motiva a análise do pensamento de Rancière, através de uma retrospectiva kierkegaardiana, é que sob essa égide metodológica se afigura possível purgar grande parte da inclinação ideológica do pensador francês, mantendose, de toda forma, o seu cerne interpretativo. Logo, é possível depreender, 
através das mais variadas formas de apresentação política do interesse, que o elemento estético é sempre prevalente na atualidade política, de maneira que existem vanguardas e retaguardas envolvidas nesse plano e que se conjugam, justamente, por meio dos elementos estéticos dispostos na análise operada. Conclui-se, portanto, que o trabalho apresentado indica uma interpretação estético-política da realidade que não rejeita, de plano, nem retaguardas tampouco vanguardas, desde que se possa ponderar adequadamente acerca dos interesses envolvidos em tais querelas.

ERICKSEN, L. Aesthetic stage, interests and politics: discussing Kierkegaard and Rancière. Trans/form/ação, Marília, v. 43, n. 1, p. 127-150, Jan./Mar., 2020.

AвSTRACT: The paper concerns the relationship between politics and aesthetics In the philosophies of Kierkegaard and Rancière. The paper debates how the interests are the key element in Kierkegaard's aesthetic stage in "comparison" to aesthetical-political context for Rancière. The paper presents the political regimes of Rancière in allusive recollection of human life stages as showed by Kierkegaard. The paper offers a study focused on the multiplicity of politics based on a vast of aesthetical interests and possibilities. The paper results in an aesthetical-political perception free from ideological aspiration, which is able to states avant-gardes and rearguards about nowadays political thinking.

KEY-WorDs: Aesthetics. Politics. Metaphysics. Rancière. Kierkegaard.

\section{REFERÊNCIAS}

BLOCH, Ernst. Aesthetics and Politics. Tradução de Ronald Taylor. London: NLB, 1977.

BREAUGH, Martin; LEDERHENDLER, Lazer. The Plebeian Experience: A

Discontinuous History of Political Freedom. New York: Columbia UP, 2013.

BROCKMAN, David R. Dialectical Democracy Through Christian Thought: Individualism, Relationalism, and American Politics. New York: Macmillan, 2013.

CAPUTO, John D. Heidegger and Aquinas: An Essay on Overcoming Metaphysics. New York: Fordham UP, 1982.

CHAMBERS, Samuel A. Jaques Rancière. In: SIMONS, Jon (org.). From Agamben to Žižek Contemporary Critical Theorists. Edinburgh: Edinburgh UP, 2010. p. 194-209.

COPJEC, Joan et al. The Worst. Buffalo: Center for the Study of Psychoanalysis and Culture, 2011.

DAVIS, Oliver. Jacques Rancière. Oxford: Wiley, 2013. 
DEMOS, T. J. The Migrant Image: The Art and Politics of Documentary During Global Crisis. Durham: Duke UP, 2013.

FEUER, Lewis S. Ideology and the Ideologists. New Brunswick, N.J.: Transaction Publishers, 2010.

HANNAY, Alastair. Kierkegaard: The Argument of the Philosophers. New York: Routledge, 1999.

HEIDEGGER, Martin. Ser e Tempo. Tradução de Márcia Sá Cavalcante Schüback. 3. ed. Rio de Janeiro: Vozes, 2008.

HIRVONEN, Ari. Reinventing European Democracy: Democratization and the Existential Crisis in EU. In: FICHERA, Massimo et al. (org.). Polity and Crisis Reflections on the European Odyssey. Burlington: Ashgate, 2014.

KIERKEGAARD, Søren. Ou bien... ou bien... Tradução de F. Prior, O. Prior e M. H. Guignot. Paris: Gallimard, 1943.

KIERKEGAARD, Søren. Estética y Ética: En la Formación de la Personalidad. Tradução de Armand Marot. Buenos Aires: Nova, 1955.

KIERKEGAARD, Søren. Post Scriptum no cientifico y definitivo a "Migajas filosóficas". Tradução de Javier Teira e Nekane Legarreta. Salamanca: Sígueme, 2010.

KIERKEGAARD, Søren. O Conceito de Angústia: Uma Simples Reflexão Psicológicodemonstrativa Direcionada ao Problema Dogmático do Pecado Hereditário de Virgilius Haufniensis. Tradução de Álvaro Valls. Petrópolis: Vozes, 2011.

LUXON, Nancy. Crisis of Authority: Politics, Trust, and Truth-Telling in Freud and Foucault. Cambridge: Cambridge UP, 2013.

MALIK, Suhail; PHILLIPS, Andrea. The Wrong of Contemporary Art: Aesthetics and Political Indeterminacy. In: BOWMAN, Paul; STAMP, Richard (org.). Reading Rancière. London: Continuum, 2011. p. 111-128.

MALPAS, Jeff. Heidegger's Topology: Being, Place, World. Cambridge: MIT Press, 2006.

MAY, Todd. Contemporary Political Movements and the Thought of Jacques Rancière: Equality in Action. Edinburgh: Edinburgh UP, 2010.

MCNAY, Lois. The Misguided Search for the Political: Social Weightlessness in Radical Democratic Theory. Cambridge: Polity, 2014.

MOONEY, Edward F. Excursions with Kierkegaard: Others, Goods, Death, and Final Faith. New York: Continuum, 2012.

RANCIÈRE, Jacques. Politicas da Escrita. Traduçâo de Raquel Ramalhete et al. Rio de Janeiro: Editora 34, 1995.

RANCIÈRE, Jacques. O Desentendimento: Política e Filosofia. Tradução de Angela Leite Lopes. São Paulo: Editora 34, 1996. 
RANCIÈRE, Jacques. The Politics of Aesthetics: The Distribution of the Sensible. Trad. Gabriel Rockhill. London: Continuum, 2004.

ROBERTS, James Deotis. Black Theology in Dialogue. Philadelphia: Westminster Press, 1987.

ROSS, Alison. Equality in the Romantic Art form: The Hegelian Background to Jacques Rancière's Aesthetics Revolution. In: DERANTY, Jean-Philippe; ROSS, Alison (org.). Jacques Rancière and the Contemporary Scene: The Philosophy of Radical Equality. New York: Continuum, 2012. p. 87-98.

SANDERS, Mike. The Poetry of Chartism: Aesthetics, Politics, History. Cambridge: Cambridge UP, 2009.

SCHILLER, Friedrich von. A Educação Estética do Homem. Tradução de Roberto Cana. São Paulo: Iluminuras, 1995.

SHAW, Devin Zane. Egalitarian Moments: From Descartes to Rancière. New York: Bloomsbury Academic, 2015.

TANKE, Joseph J. Jacques Rancière: An Introduction, Philosophy, Politics, Aesthetics. London: Continuum, 2011.

VADÉN, Tere. Heidegger, Žižek and Revolution. Rotterdam: Sense, 2014.

VÉGSÖ, Roland. The Naked Communist: Cold War Modernism and the Politics of Popular Culture. New York: Fordham UP, 2013.

VIESTENZ, William. By the Grace of God: Francoist Spain and the Sacred Roots of Political Imagination. Toronto: University of Toronto Press, 2014.

WILLIS, Gary. The Key Issues Concerning Contemporary Art: Philosophy, Politics and Popular Culture in the Context of Contemporary Cultural Practice. Melbourne: Melbourne University Custom Book Centre, 2010.

Recebido: 11/12/2016

Aceito: 11/04/2019 